Vegueta. Anuario de la Facultad de Geografía e Historia

$21(2), 2021,59-78$

eISSN: 2341-1112

https://doi.org/10.51349/veg.2021.2.03

\title{
Cartografía digital disidente: El caso de Santiago de Chile durante el estallido social de 2019
}

\author{
Dissident Digital Cartography: \\ The Case of Santiago de Chile during the Social Outburst of 2019
}

\author{
Víctor Jiménez Barrado \\ Pontificia Universidad Católica de Chile \\ Instituto de Geografía \\ https://orcid.org/0000-0001-7064-7465 \\ victor.jimenez@uc.cl
}

Recibido: 02/10/2020; Revisado: 14/12/2020; Aceptado: 11/03/2021

\section{Resumen}

El 18 de octubre de 2019 estalló en Santiago de Chile una de las mayores crisis sociales de la historia reciente del país. En un contexto de represión estatal y de desinformación surgieron múltiples iniciativas dedicadas a reunir colaborativamente información espacial, mayoritariamente apoyadas en las nuevas tecnologías. El objetivo de este trabajo es descubrir su significado y utilidad. Para ello se han identificado y analizado estos registros cartográficos mediante la observación participante no impostada en redes sociales. Los resultados muestran la cartografía digital como una estrategia de cuidado mutuo, un entorno de lucha y un hito fundamental para su continuidad.

Palabras clave: Cartografía colaborativa, Chile, ciudad, lucha social, modelo neoliberal.

\begin{abstract}
On the 18th October 2019, one of the biggest social crises in Chile's recent history broke out in its capital Santiago. Against a backdrop of state repression and disinformation, there emerged multiple collaborative initiatives, largely based on new technologies, to collate spatial information. The objective of this article is to discover this collation's significance and usefulness. As such, these cartographic records have been identified and analysed by way of genuine participatory observation within social networks. The results present digital cartography as a strategy of mutual care, an arena for struggle and a fundamental milestone in its continuity.
\end{abstract}

Keywords: Collaborative Mapping, Chile, The City, Social Struggle, Neo-Liberal Model. 


\section{INTRODUCCIÓN}

\subsection{Indicadores del éxito neoliberal chileno: la cara macroeconómica de La Moneda}

Chile ha sido reconocido internacionalmente como uno de los laboratorios iniciales y, por ende, cancha inaugural del modelo neoliberal (HARVEY, 2007; Stiglitz, 2012). Las recetas de la teoría económica, condensadas en el «ladrillo» de los Chicago Boys (De CASTRO y MéndeZ, 1992), se implantaron forzosamente desde 1973, por un gobierno dictatorial y militar (instrumento sine qua non) con apoyo exterior (HARVEY, 2012; JANOSCHKA e HIDALGO, 2014), hasta 1990. Entre tanto, estos ideales se consolidaron mediante la Constitución política del Estado de 1980, que fue transferida sin solución de continuidad al sistema democrático, quedando, hasta la fecha, vigente con algunas modificaciones.

La Carta Magna es, por lo tanto, pilar fundamental para la reproducción y supervivencia de un sistema que, si bien es hegemónico en el mundo, muestra en Chile trazos singulares de máxima radicalidad.

De ella se descuelga todo un corpus legal que otorga a gran parte de los bienes nacionales de uso público un estatus de "transabilidad» en el libre mercado. Así ocurre con el agua, en cuyo código regulador se establece la propiedad privada del derecho de su aprovechamiento, lo cual no sólo choca con la cosmovisión indígena (Di Giminiani y GonZÁLeZ, 2018), sino además con resoluciones específicas de la ONU que reconocen el derecho humano al agua. ${ }^{1}$ Algo similar ocurre en el acceso a la sanidad, degradada de servicio público a bien de consumo (SAKELlariou y RotAROU, 2017), o con el sistema educativo, que ha fomentado a partes iguales la metamorfosis social temprana en deudor crediticio y las protestas estudiantiles contra el modelo (CinI y GUZMÁN-CONCHA, 2017; INZUNZA ET AL., 2019).

Con estos mimbres, el país andino ha conseguido unos óptimos datos macroeconómicos, particularmente importantes dentro de su contexto regional. Sus logros se condensan en una tasa de desempleo que no sube del $8,5 \%$ en los últimos 9 años (datos de la Encuesta Nacional de Empleo) y su posición cuadragésimo-segunda a nivel mundial como país con mayor Producto Interior Bruto según los datos del Fondo Monetario Internacional, ocupando el mismo lugar en términos del Índice de Desarrollo Humano y el $53^{\circ}$ en cuanto a PIB per cápita. Ejemplo de su fortaleza macroeconómica es que aproximadamente una década atrás, la coincidencia de tres factores (extrema apertura económica debido al modelo neoliberal, amplias reservas de mineral al norte del país -Chile es el país con mayor producción y reservas de cobre a nivel mundial- y el desarrollo productivo-tecnológico de China, principal socio exportador e importador) le permitieron superar rápidamente, a través de su sistema extractivista-exportador, la crisis global iniciada en 2007 (HARVEY, 2019).

Junto con esto, la deuda pública económica es muy baja con relación al PIB $(25,56 \%)$, pero se dispara si atendemos a la deuda de lo público y sus instituciones con la sociedad, entendiendo esto como la obligación del Estado chileno de proveer

1 La Resolución 64/292 de la Asamblea General de las Naciones Unidas reconoció el 28 de julio de 2010 el derecho humano al agua y al saneamiento, haciendo hincapié en la importancia de disponer de agua potable y saneamiento en condiciones equitativas como componente esencial del disfrute de todos los derechos humanos. 
a sus ciudadanos de igualdad de oportunidades (Artículo 1 de la Constitución política de la República de Chile).

El presente artículo se organiza desde la presentación inicial de las causas principales que han promovido el estallido social y por ende, la cartografía estudiada. Se exponen las contradicciones de un modelo que, como ya se ha explicado, es exitoso en el nivel macroeconómico pero que a medida que se aproxima a la escala humana se torna deficitario, teniendo expresiones espaciales claras. Desde ese punto se parte hacia una explicación metodológica para, posteriormente, presentar y discutir los resultados (cartografías, características y protagonistas) y finalmente alcanzar unas conclusiones sobre el significado de esta producción de cartografía digital disidente en Chile.

\subsection{La polarización social y la precariedad: el revés desigual de la moneda.}

El citado triunfo macroeconómico chileno ha obtenido notables resultados, entre ellos la rápida reducción de la pobreza. Según la encuesta CASEN, el porcentaje de personas en situación de pobreza y pobreza extrema en Chile ha pasado de un $16,5 \%$ y $12,6 \%$ respectivamente en el año 2006 a un $6,3 \%$ y un $2,3 \%$ en 2017. Estas cifras reflejan un veloz aumento de la clase media, que se ha convertido en la base social del país. Un grupo socioeconómico que, además de representar una fuerza de trabajo barata, es el grueso de la demanda nacional de bienes y servicios.

El despojo comienza en la institucionalidad. El Estado chileno es un Estado subsidiario, apoyado en la máxima teórica de que éste sólo debe actuar en ausencia de la iniciativa privada, pero que en la práctica obliga a que sea la población la que subsidie sus responsabilidades mínimas (BORGIAS, 2018). Esto se muestra en la labor fiscalizadora de las asociaciones y las ONGs contra los abusos, pero también en el rol que la solidaridad popular ejerce como muleta del neoliberalismo, haciéndose cargo de primeras necesidades en materia de educación o sanidad, siendo la Teletón ${ }^{2}$ un ejemplo paradigmático de la integración de la beneficencia en el sistema neoliberal (HUMERES, 2019). Un sistema basado en el individualismo radical tal y como lo describe De Julios (1995), que necesita de la sumisión y del convencimiento del individuo, actuando éste como célula del organismo neoliberal nacional. Así, el manejo elevado de anglicismos económicos (o relacionados con el consumo masivo) del chileno promedio (Gerding, Fuentes y Kotz, 2012) es un indicio de la primacía de lo económico, aunque este conocimiento no se corresponda con una educación familiar y académica en buenas prácticas (DENEGRI ET AL., 2005), entendiendo como tales el fomento del ahorro y el abandono de un consumo compulsivo apoyado en el crédito. De hecho, según los datos del Banco Central de Chile, la deuda de los hogares aumentó en sólo 4 años (20152019) desde el $65,9 \%$ al $74,3 \%$ del ingreso disponible. Bajo esta dinámica, el ingreso fijo mensual a través de la renta laboral se hace completamente necesario, dependencia que se encona en una etapa crítica como la de jubilación. En ella, los gastos sanitarios aumentan mientras la capacidad financiera se ve muy reducida debido a la insuficiencia económica que genera el actual sistema de pensiones privado, obligatoriamente gestionado por las Administradoras de Fondos de

2 Inspirado en el evento televisivo estadounidense Telethon, presentado por Jerry Lewis. 
Pensiones (AFP) ${ }^{3}$ (VIVEs et al., 2016).

Así, en un contexto de libre empresa y protección a ultranza de la propiedad privada, sin mero atisbo de su función social, se gesta el caldo de cultivo de la polarización socioeconómica. Chile es, junto con México, el país con mayor desigualdad de la OCDE (KeELeY, 2018). Un coeficiente de Gini por sobre 0,45 desvela que el reparto de la riqueza y la reducción de la brecha social son materias pendientes del modelo y del país. Esto coincide con los informes de CEPAL (2019), los cuales indican que el 1\% más acaudalado de la población chilena concentra más de un cuarto de la riqueza $(26,5 \%)$, mientras que la mitad más pobre de la población sólo retiene un 2,1\% de la riqueza.

El modelo neoliberal extractivista de los recursos naturales (basado en la minería, principalmente de cobre), ${ }^{4}$ también lo es de su proletariado, compuesto por una amplia base de clase media endeudada. Es decir, un estrato socioeconómico cuya capacidad de consumo se sustenta en el crédito más que en sus rentas salariales.

Por supuesto, este expolio no se refiere a los recursos retraídos por el Estado del salario a través de la vía impositiva, que con un $7 \%$ en promedio son -por mucho- los más bajos de la $\mathrm{OCDE},{ }^{5}$ sino a la diferencia en términos de plusvalía que le otorga al sector privado un nivel de salarios mensuales promedio en 2018 de 652.397 pesos chilenos. Esta cifra esconde una realidad más depredadora y precarizada, puesto que el ingreso mediano se sitúa en 411.100 pesos chilenos, dentro de un contexto de servicios públicos básicos (educación, sanidad y pensiones) privatizados y un coste de la canasta básica de alimentos de 43.091 pesos chilenos por persona (10,48\% del ingreso mediano mensual).

\subsection{El canto de la moneda: territorio y ciudad, voceros de la desigualdad.}

Espacialmente la inequidad se muestra sin tapujos en Chile, con una amplia disparidad regional en cuanto a PIB per cápita (Figura 1), indicador que, por otro lado, sesga la realidad individual. El país está desprovisto de políticas e instrumentos redistributivos en lo espacial, tales como una Política Nacional de Ordenación del Territorio y una planificación territorial regional -Planes Regionales de Ordenamiento Territorial- (MATURANA et al., 2017). Esta ausencia deja a los territorios (y sus pobladores) a la deriva, a la vez que ahonda, aún más, en las problemáticas consecuencias de la grave inequidad y segregación socioespacial chilena.

\footnotetext{
3 El sistema de AFP, creado en 1980 por José Piñera (hermano del actual presidente de la República) es una de las 7 famosas modernizaciones que la Junta Militar dictatorial implantó en Chile para consolidar el modelo neoliberal. A esta medida le acompañan otras como un nuevo plan laboral, la reforma educativa, sanitaria y judicial, el reordenamiento de la propiedad privada agrícola y la reforma administrativa para adelgazar el Estado.

4 En atención a los datos del Banco Central de Chile, sólo en el año 2017, las exportaciones del sector minero chileno alcanzaron un precio de 68.306,1 millones de dólares americanos, lo que significó multiplicar por 7 las exportaciones del sector primario para el mismo periodo.

5 El promedio de la OCDE en el año 2017 es del 25,5\%. El registro más aproximado a nivel nacional procede del otro país latinoamericano integrante de la OCDE, México (11,2\%).
} 

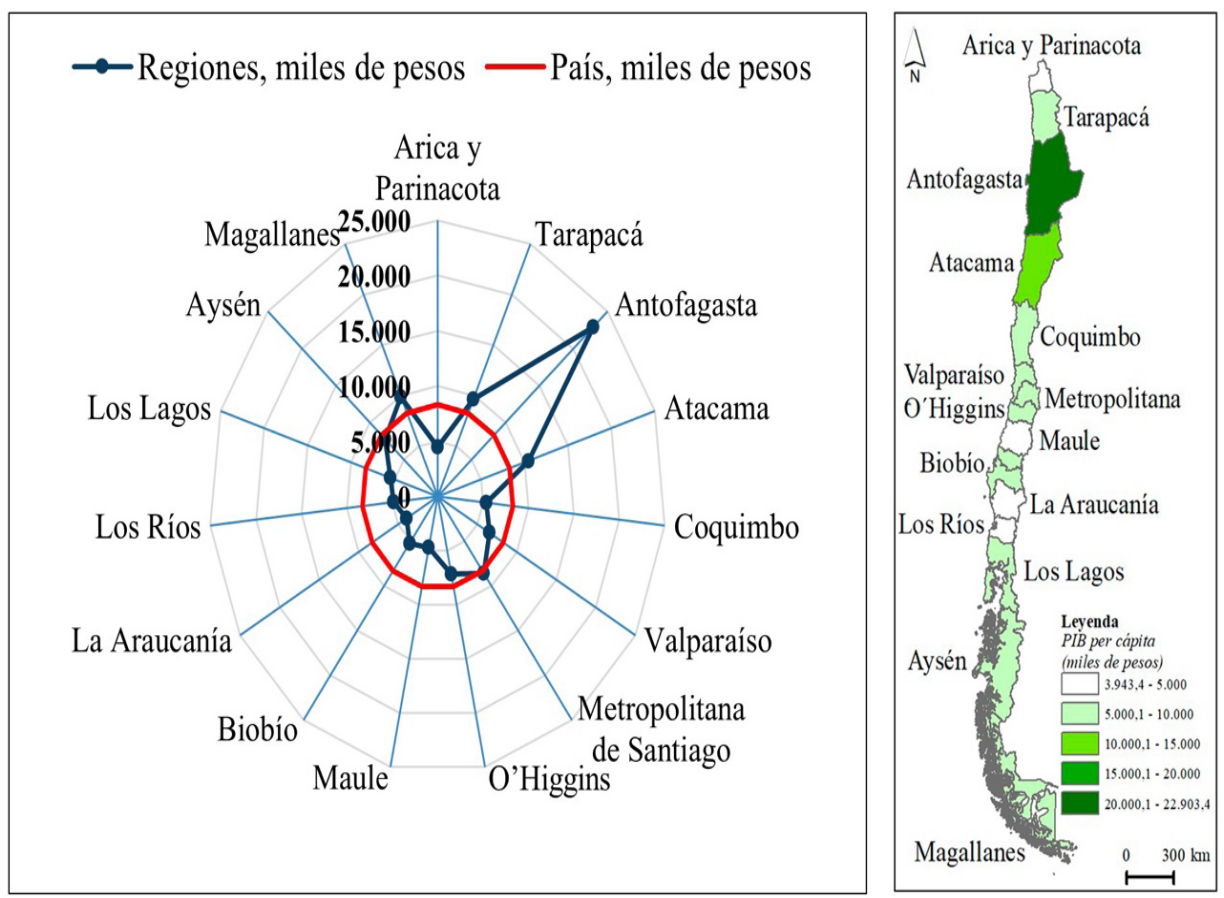

Figura 1. PIB per cápita en las regiones chilenas. Elaboración propia. 2019

Dentro de una agenda político-normativa liberal y centralista esto supone la explotación sin fin de la naturaleza en regiones (tales como Antofagasta, rica en recursos minerales) y la concentración de capitales públicos y privados en Santiago, a la que sigue una corriente demográfica. Este actuar centrípeto se mantiene aun cuando existen recientes medidas "descentralizadoras» (Ley $\mathrm{N}^{\circ}$ 21.074 para el fortalecimiento de la regionalización del país), por cuanto éstas no comportan una autonomía presupuestaria en dichas escalas que proporcione libertad de acción a sus gobiernos.

Por su parte, las políticas urbanas en Chile han estado altamente ideologizadas durante los últimos 50 años (NAvarrete-Hernández y Toro, 2019). Se han combinado periodos dónde se primaba la búsqueda de la igualdad (1952-1973) o donde sólo el mercado guiaba los criterios de ocupación del suelo (1973-1989), seguidos de otro donde se trataba de mitigar, con giros improvisados (Román y BARTON, 2018), la segregación socio-espacial (1990-2010), para final y recientemente volver a una hegemonía economicista.

Así, el status quo aúpa a la capital a una macrocefalia donde se sintomatiza de forma más clara (por su proximidad) la desigualdad (Figura 2). El «cono de alta renta ${ }^{6}$ es parte del lenguaje e imaginario social, a la vez que muestra y vector

6 El sector con mayor nivel socioeconómico en Santiago de Chile está conformado por las comunas 
que explica el patrón espacial de segregación socio-espacial en la capital. Según el reciente índice PICSA (2019), referido a esta variable, la gran metrópoli chilena ocupa el puesto $93^{\circ}$ a nivel mundial, la sexta en el contexto latinoamericano.

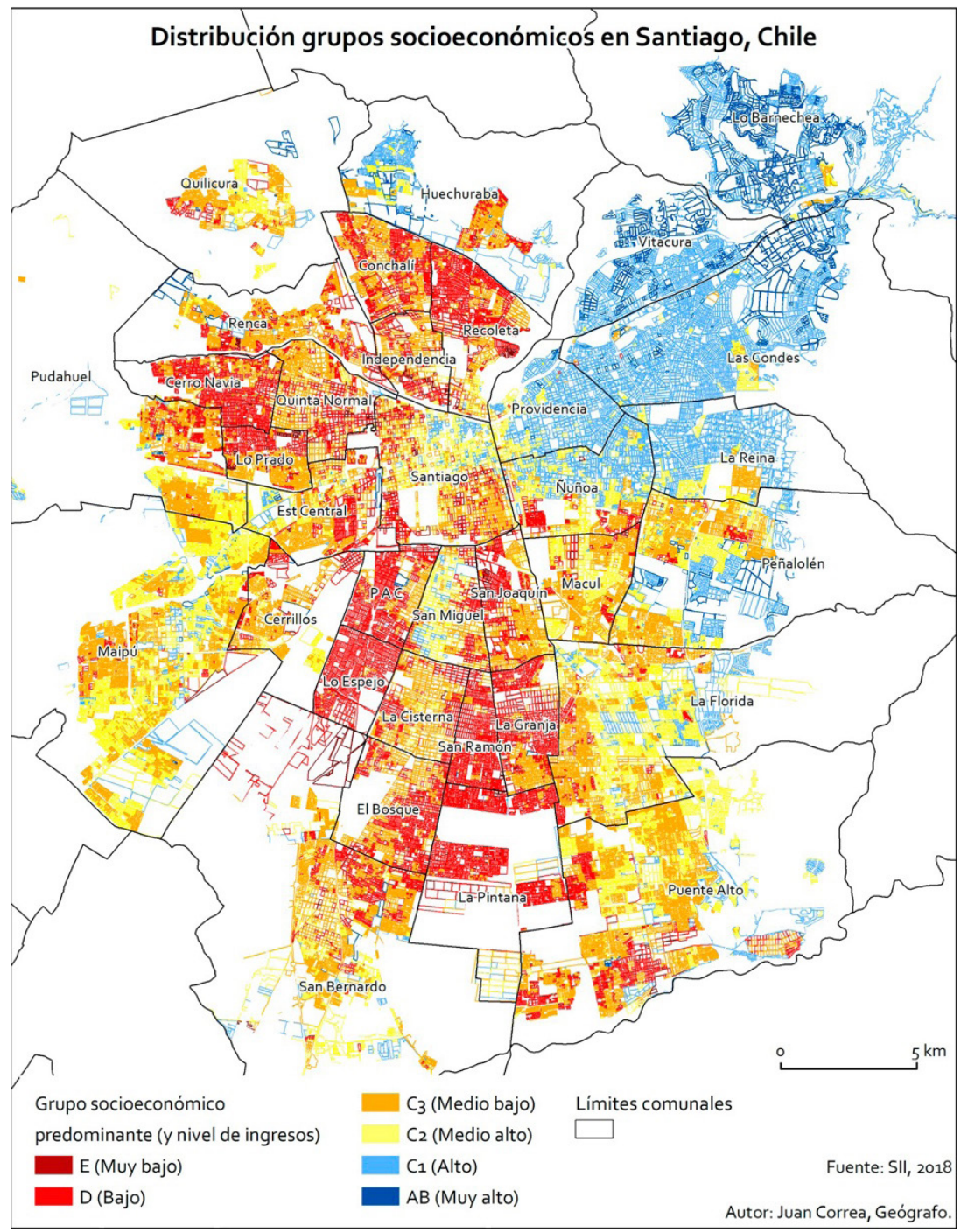

Figura 2. Distribución espacial de los grupos socioeconómicos en Santiago de Chile (CORREA, 2018). ${ }^{7}$

orientales de Providencial, Vitacura, Lo Barnechea y Las Condes, principalmente. A este se suman las comunas de La Reina y Ñuñoa, por la pujanza de sus secciones más septentrionales y orientales. 7 CorreA, J. [@Juanizio_C]. 2018. [Twitter]. 
En ella, comunas del citado "cono de alta renta" (ubicado al noreste), como Vitacura, exhiben un nivel de ingresos promedio más de cinco veces superior al de comunas como Pedro Aguirre Cerdá (PAC), situada a apenas 8,5 kilómetros en línea recta. Tal diferencia se llega a conceptualizar como otro signo más de «violencia estatal» (ANIÑIR y CANDINA, 2020; PIZARro, 2020) que alimenta levantamientos populares como el ocurrido. Junto a esta disparidad, tanto el Censo más reciente (2017) como la encuesta CASEN ofrecen un panorama capitalino muy polarizado en el que ese grupo de sólo seis comunas presenta un perfil muy diferente del resto. Esto alcanza a cuestiones tales como el tipo de actividad predominante, con una clara hegemonía del sector terciario, pero también a los perfiles profesionales que habitan este espacio (gran concentración relativa de intelectuales y profesionales relacionados con las altas instituciones políticas, judiciales, educativas y empresariales). Este retrato socioeconómico afecta finalmente a cuestiones materiales como una menor dificultad de acceso a servicios básicos (educación, sanidad, habitabilidad, etc.), lo que en síntesis divide la ciudad en un espacio privilegiado y otro, más amplio, que queda relegado en múltiples dimensiones.

Por lo tanto, Santiago es paradigma de la ciudad neoliberal gracias a un modelo que lejos de reconocer el derecho a la ciudad, no garantiza si quiera el derecho a la vivienda digna (BRUEY, 2012). De hecho, cuando éste se ha provisto de manera subsidiada por el Estado, se ha realizado de nuevo bajo un paradigma individualista y competitivo, disfrazado de mecanismo participativo y autogestionado, tal y como lo concibe MuÑOz (2007). La realidad es que las políticas de "rostro humano" (Atria, 2013; Hidalgo, Alvarado y Santana, 2017; TAPIA, 2018) han estado más preocupadas de salvar objetivos cuantitativos que cualitativos, resultando analgésicas. Por esta razón, la producción de viviendas sociales fue un éxito de cara a subsanar el déficit habitacional (Hidalgo, 1999), aunque cimentó las bases de un modelo urbanístico guettificado. Sustancial en el entendimiento de esta configuración metropolitana son también las operaciones traumáticas como las erradicaciones de poblaciones, la densificación urbana en gran altura, y la reestructuración del transporte público y las autovías urbanas (GARRETON, 2017).

En consecuencia, la liberalización del suelo, instrumentalizada y normalizada (JIMÉNEZ et al., 2018), permite a las élites elegir preferentemente la ubicación y la morfología urbana, mientras que las clases populares se resignan a un nuevo TINA (There Is No Alternative), puesto que sus condiciones pretéritas son mucho más precarias, como las tomas o los campamentos. Bajo estas condiciones, existe una clara estigmatización social fundamentada en el lugar de residencia (MÉNDEZ y OTERO, 2018), en el que las unidades barriales se enclaustran y compiten entre ellas (LETELIER et al., 2019), alejando el desarrollo integral e integrado de la ciudad, que carece de gobierno metropolitano.

Existen certezas de que esta desigualdad social repercute en una crisis de representatividad, que aleja del juego democrático particularmente a las clases sociales más perjudicadas (también las más numerosas) por el sistema (FERNÁNDEZ, MANUEl-NAVARRETE y TorRes-SALINAS, 2016), y que se ve agravada por una histórica falta de diálogo entre el Estado y su sociedad (GuTIÉRREZ, 2020). En este clima de angustia individual, descontento popular y falta de representatividad estalló en Santiago un movimiento social que, como se ha expuesto, no es atribuible en exclusiva al alza de 30 pesos en el billete de metro, sino a 30 años en los que 
se apuntalan las condiciones explicadas. Las protestas sociales comenzaron de forma incipiente durante los días 17, 18 y 19 de octubre de 2019, siendo la jornada del viernes 18 la de mayor movilización social de la historia reciente de Chile, con epicentro en la céntrica Plaza Baquedano de la capital y replicada en la mayor parte de las ciudades del país. Desde ese momento, la lucha se extendió temporal y espacialmente, sin un abanderado o interlocutor político. Durante meses (sin interrupción diaria) y en todos los rincones del país, las formas de protesta más comunes fueron la evasión de los pasajes de metro, las caceroladas diurnas en las calles y nocturnas en las casas, las concentraciones en la vía pública (masivas los días viernes), la celebración de cabildos (asambleas populares autoconvocadas) y foros vecinales de participación trasversal, etc. Pero en los primeros días y semanas, las protestas también incluían luchas en las calles entre civiles y cuerpos policiales, lo que provocó inseguridad tanto por sus características, como por la represión violenta de Carabineros (cuerpo nacional de policía) y el ejército, que conllevó fallecidos civiles. Es en este peligroso escenario cuando y donde aparece la cartografía colaborativa del estallido social.

El presente trabajo toma como objetivo principal conocer las características principales de esta cartografía novedosa apoyada en las nuevas tecnologías, tratando de, esencialmente, descubrir su origen y significado. Si bien la causa inmediata de este hecho histórico fue la, en principio nimia, subida de los pasajes de metro, la consecuencia más relevante será la creación de un nuevo marco constitucional para Chile, de ahí la importancia de estudiar todos los elementos que ayudaron a crear esta coyuntura refundacional y modernizadora del país.

\section{METODOLOGÍA}

El proceso metodológico responde a las características específicas de la cartografía motivada por el estallido social en Chile y producida entre el 18 de octubre y el 30 de noviembre de 2019, así como a las circunstancias del investigador durante los acontecimientos. Consiguientemente, la observación participante no estructurada ni inducida se erige como el método más adecuado y factible. La espontaneidad, inmediatez y novedad de la cartografía, al igual que su potencial fugacidad, impide una recopilación de datos y fuentes etapizada y ordenada previamente. Además, la condición de académico, geógrafo y residente santiaguino del autor, lo sitúa en una posición no impostada, preexistente e integrada en redes profesionales, académicas y sociales vinculadas a la producción cartográfica, lo cual ha facilitado el acceso a la información.

La eventualidad provoca que los datos no tengan fuentes precisas, acotadas ni anteriormente reconocidas. Por ello, el primer paso es identificar y acceder a las mismas. Esto se realizó por dos vías; una marginal, a través de notificaciones en redes profesionales y/o académicas (vía correo electrónico), las cuales dieron aviso de iniciativas cartográficas al respecto (algunas de ellas surgidas desde la propia casa académica); y otra, general, mediante el seguimiento de redes sociales (RRSS) hasta el final de noviembre. Para esto último se simuló la actividad diaria de un usuario de Twitter durante los acontecimientos (con mayor intensidad de consultas durante la semana del 18 al 25 de octubre), reportando información espacial derivada de la búsqueda por eventos y localizaciones que, por experiencia 
vivencial o aparición en medios de comunicación, eran relevantes. Adicionalmente, se hizo uso durante todo el proceso del listado de tendencias en Chile (Trending Topics), realizando búsquedas sobre las publicaciones asociadas a etiquetas (hashtags) más recurrentes, aun cuando habían perdido la condición de «tema más comentado» según el listado que ofrece la propia red social. Entre ellas destacan las referidas a lugares específicos (\#PlazaDignidad, \#barricadas, estaciones de metro, etc.), eventos concretos (\#toquedequeda; \#EstadoDeExcepcion) o generales (\#RenunciaPiñera; \#EvasionMasivaTodoElDia; \#LaMarchaMasGrandedeChile) e, incluso, algunas que coincidentemente fueron útiles (\#30DayMapChallenge).

Para ampliar la base de datos, esta búsqueda fue replicada en términos, periodo y cadencia en Instagram. Cuando las etiquetas coincidían con lugares exactos, se procedía a realizar una búsqueda de publicaciones geolocalizadas.

$\mathrm{Si}$ bien este procedimiento genera incertidumbre ante la representatividad de la muestra, sí es prueba de que lo aquí examinado compone el grueso y parte más accesible (y, por consiguiente, utilizada por la población) de la cartografía generada a tenor de la crisis social.

Esta búsqueda entregó resultados directos sobre cartografía en muy pocas ocasiones, aunque ha resultado útil para identificar los mapas más relevantes, pero fundamentalmente, las fuentes y usuarios más activos (asociaciones, colectivos y personas), cuyos procesos y/o productos cartográficos se servían adicional o exclusivamente en otras plataformas como Google Maps y sus derivados. Estos mismos resultados han propiciado un posterior muestreo en «bola de nieve», que ha permitido localizar nuevos agentes que ayudaban a cartografiar lo ocurrido, encontrando coyunturalmente experiencias de otras ciudades chilenas o que rebasan la escala urbana, las cuales han sido depuradas mediante Sistemas de Información Geográfica (conversión de capas KML o KMZ a formato shapefile y selección y examen de datos referidos en particular a Santiago).

Finalmente, una vez acotadas las fuentes y cartografías, en este trabajo se muestra una relación de ellas, ${ }^{8}$ acompañadas de un examen sobre su origen, disponibilidad, medios de promoción y difusión. Junto con esto, se indaga en su contenido y su potencial significado y utilidad durante o después de las protestas.

\section{RESULTADOS}

La resistencia popular chilena atesora una gran tradición que hunde sus raíces de lucha contemporánea en las Jornadas Nacionales de Protesta celebradas durante los años 80, retomadas periódicamente en democracia para seguir haciendo frente al modelo neoliberal (alza en el coste de los servicios, sistemas privados de salud, educación y pensiones, sobre-explotación de la naturaleza, discriminación a los pueblos indígenas y otras minorías, etc.).

Los acontecimientos de octubre y noviembre de 2019 encuentran notables paralelismos con las citadas jornadas, tanto en las formas de las protestas (barricadas, saqueos y masivas manifestaciones pacíficas) como en los métodos represivos por parte del Estado (BRAVO, 2012). Entre estos métodos se incluyen

8 Aquellas cartografías en construcción o en constante producción han sido examinadas según su estado a 30 de noviembre de 2019, independientemente de que se refieran a un periodo temporal concreto o no. 
la declaración del Estado de Emergencia y toque de queda, miles de detenidos, decenas de muertes civiles y violaciones a los derechos humanos por parte de cuerpos policiales y militares (ACNUDH, 2019).

Al igual que en el año 2006 con el movimiento pingüino, la reivindicación de octubre de 2019 parte de los estudiantes secundarios (DISI, 2018), aunque esta vez gatillados por una cuestión que no les afecta directamente en lo inmediato, ${ }^{9}$ sino movidos por la solidaridad intergeneracional.

Al margen de estas similitudes, en la actualidad, la presencia extendida de dispositivos móviles con acceso a internet en Chile ha significado un elemento diferenciador clave a la hora de oponer resistencia. Los avances tecnológicos facilitan la organización popular y le aportan sencillez, a la vez que ayudan a contrarrestar el discurso oficialista en un ámbito global. En términos cartográficos esto significa que el proceso "mapeador» nace y se instala en la resistencia al oficialismo, sin una de las principales limitaciones para su éxito, es decir, las dificultades de acceso a la red o los dispositivos que la proveen (SULLIVANWiley, Short y Casellas, 2019; Nicolosi, French y Medina, 2019). Todo proceso cartográfico de este tipo requiere de «información geográfica voluntaria», con la particularidad de que en Chile los "prosumidores» (RITZER y JURGENSON, 2010) lo han sido en directo.

Así, una de las cartografías más relevantes y útiles fue la promovida por el "Colectivo de Geografía Crítica Gladys Armijo», que recopiló y publicó prácticamente en tiempo real sucesos durante los momentos más álgidos del estallido. Se trata de una cartografía de tipo colaborativo a la que se suman aportes voluntarios captados en RRSS (Twitter e Instagram), utilizadas también como medio de difusión. La información espacial se aloja en los servidores de Google, de acceso y uso gratuito, a través de su herramienta multiplataforma «My Maps». La Figura 3 muestra una síntesis del tipo de contenidos recopilados entre las jornadas del día 18 de octubre y 24 de octubre de 2019 en la ciudad de Santiago.

9 Los estudiantes secundarios chilenos, popularmente denominados pingüinos por su vestimenta, disponen de una Tarjeta Nacional Estudiantil (TNE) que los beneficia con una tarifa reducida en el transporte público. 


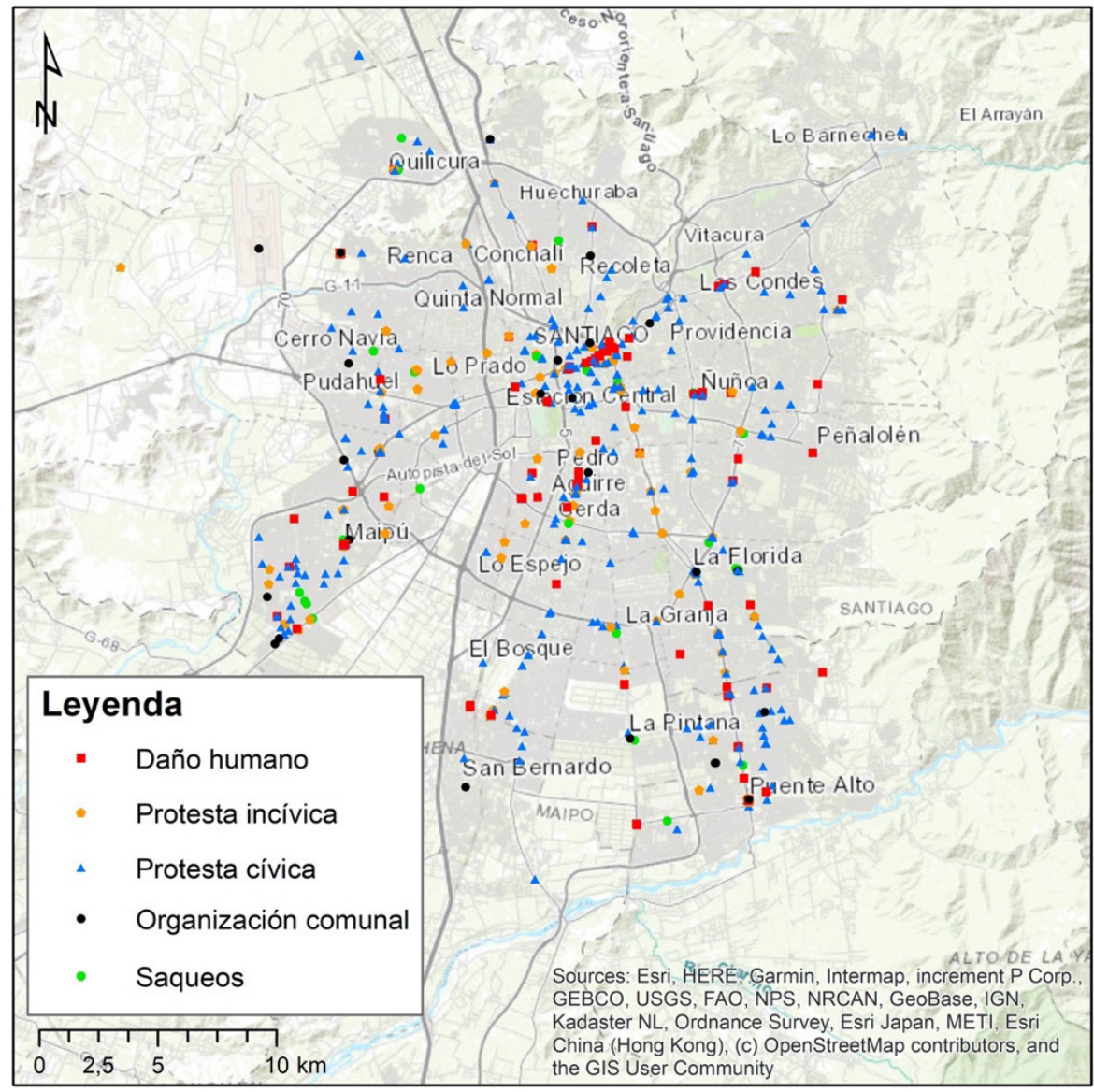

Figura 3. Información espacial colaborativa del estallido social. Elaboración propia a partir de Geografía Crítica Gladys Armijo. 2019

La información, que es descargable, se presenta mayoritariamente en topología de puntos (existen topologías de líneas para representar marchas y otras formas de resistencia) y se compartimenta fundamentalmente por periodos temporales y espacios (escala urbana, nacional e internacional), aunque también existen algunas dedicadas a temáticas específicas (muertes, daños oculares y movilizaciones). Su fácil e intuitiva leyenda y manejo facilita su comprensión y transversalidad social, lo que, combinado con su viable consulta en dispositivos móviles, potencia su uso.

Entre los mapas referidos a la capital destacan el de las jornadas del 18 y 19 de octubre, así como las del 20, 21, 22, 23 y 24 del mismo mes (incluidas dentro del periodo de toque de queda declarado), teniendo estas últimas cuatro fechas una cobertura nacional. Su contenido varía, ampliándose y reduciéndose (Tabla 1) en función del propósito declarado del colectivo en su web: «la difusión de la 
protesta en el mapa tiene por objetivo visibilizar situaciones que la prensa está ocultando».

Este «mapa dinámico» se convierte así en una herramienta que, según definen sus creadores, lucha contra la criminalización de la protesta popular generada por el gobierno y los grandes grupos mediáticos. Esto se combina con su utilidad para la ciudadanía, basada en el libre acceso, pero impidiendo su aprovechamiento por las fuerzas policiales al resguardar el anonimato de lo reportado y sus protagonistas, así como de los informantes. De este modo, los muy mediatizados daños en las estaciones de metro dejan de referirse, para incluir progresivamente otros registros menos expuestos a la opinión pública como muertes, represión policial, centros de torturas, así como nuevas formas de protesta y organización (huelgas y cabildos).

En esta última línea avanza otra iniciativa, esta vez constituida ex profeso por un conjunto de geógrafos agrupados bajo el nombre de "Geo Constituyente», en la que se determina la fecha, hora y lugar de celebración de cabildos, a lo que se suma la entidad o grupo de personas convocantes. Al igual que el anterior, es un mapa colaborativo de acceso libre que utiliza la plataforma de Google My Maps, aunque esta vez restringe a Instagram su forma de captar y difundir la información.

Su razón de ser es el fomento (a través de la publicitación centralizada) de la participación en estos enclaves y eventos de representación de la soberanía popular, en contestación a la inacción gubernamental.

TABla 1

Contenido de la cartografía colaborativa del Colectivo Geografía Crítica Gladys Armijo

\begin{tabular}{|l|c|c|c|c|c|c|c|}
\hline 18 y 19 octubre & \multicolumn{2}{|c|}{20 octubre } & 21 y 22 octubre & \multicolumn{2}{|c|}{23 y 24 octubre } \\
\hline Evento & Magnitud & $\mathrm{E}$ & $\mathrm{M}$ & $\mathrm{E}$ & $\mathrm{M}$ & $\mathrm{E}$ & $\mathrm{M}$ \\
\hline $\begin{array}{l}\text { Estaciones de } \\
\text { metro con daños }\end{array}$ & 31 & & & & & & \\
\hline Cacerolazos & 89 & & 23 & & 78 & & 50 \\
\hline $\begin{array}{l}\text { Recuperaciones/ } \\
\text { Saqueos }\end{array}$ & 31 & & & & & & 5 \\
\hline $\begin{array}{l}\text { Disparos: Balas/ } \\
\text { Perdigones }\end{array}$ & 14 & & 11 & & 16 & & 21 \\
\hline $\begin{array}{l}\text { Resistencia al } \\
\text { toque de queda }\end{array}$ & 60 & & 20 & & 53 & & 2 \\
\hline Quema de buses & 6 & & & & & & \\
\hline $\begin{array}{l}\text { B a r r i c a d a s / } \\
\text { Quemas }\end{array}$ & 46 & & 7 & & & & \\
\hline $\begin{array}{l}\text { In m u e b 1 e s } \\
\text { incendiados }\end{array}$ & 6 & & 4 & & & & \\
\hline
\end{tabular}


Víctor Jiménez Barrado

\begin{tabular}{|c|c|c|c|c|c|c|c|}
\hline & & $\begin{array}{c}\text { Situaciones } \\
\text { emergentes }\end{array}$ & 6 & & 11 & & 2 \\
\hline & & & $\begin{array}{c}\text { Centro de } \\
\text { torturas }\end{array}$ & 2 & & 1 \\
\hline & & & & $\begin{array}{c}\text { Represión } \\
\text { policial }\end{array}$ & 31 & & 4 \\
\hline & & & & & $\begin{array}{c}\text { Huelga } \\
\text { Nacional }\end{array}$ & 7 \\
\hline & & & & & & $\begin{array}{c}\text { Convocatoria } \\
\text { de cabildo }\end{array}$ & 11 \\
\hline
\end{tabular}

Fuente: Geografía Crítica Gladys Armijo. Elaboración propia.

Según la consulta del 3 de noviembre de 2020 a esta cartografía, en Chile habían sido convocados hasta 416 cabildos, de los cuales 193 tenían como sede la capital. Con esta labor que aún continúa (Figura 4), no sólo se favorece la participación sino también la continuidad de la protesta y la discusión acerca de la Constitución, tema inicialmente rechazado por el gobierno nacional.

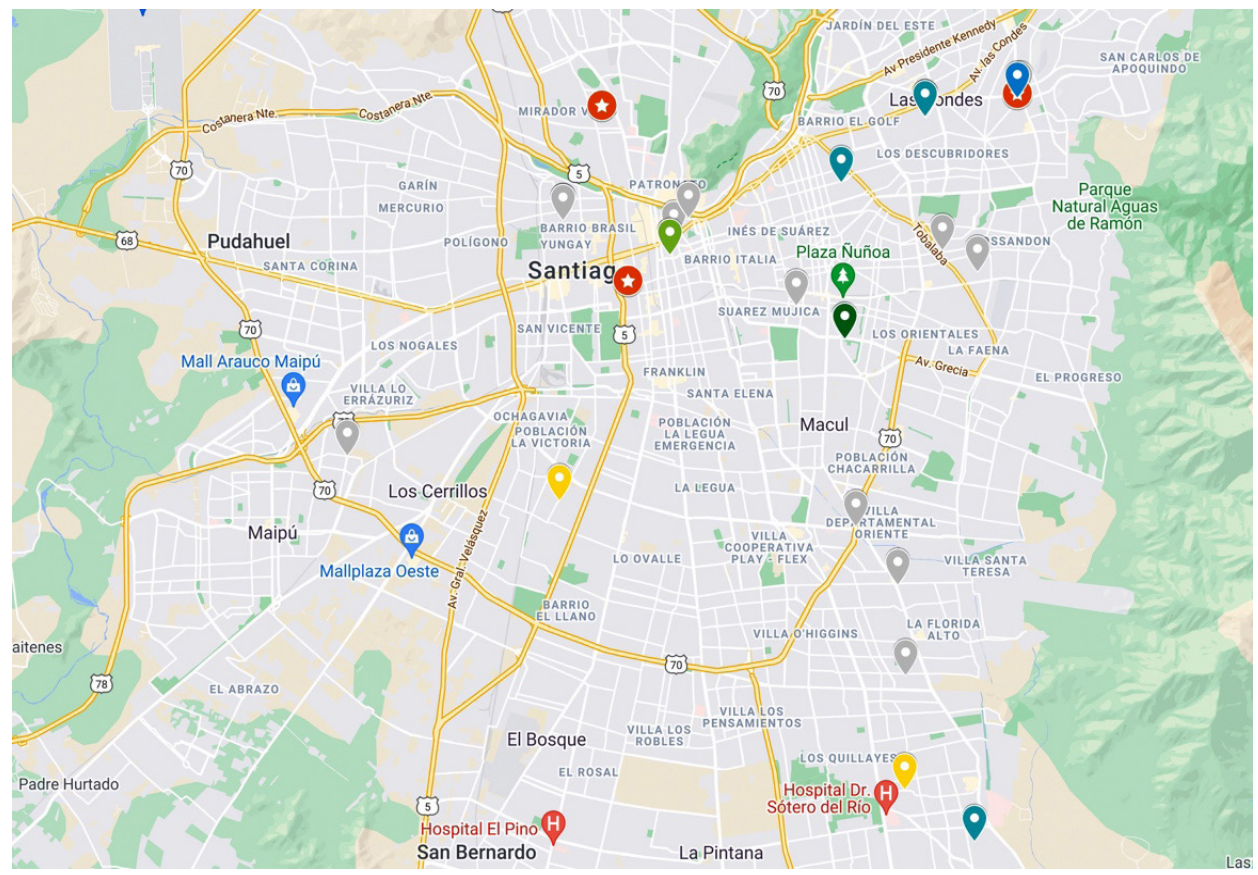

Figura 4. Mapa colaborativo de cabildos y asambleas autoconvocadas en Chile.

Geo Constituyente. 2018 
Esto demuestra que la cartografía responde a una orfandad social con respecto al gobierno, la cual se recrudeció en momentos críticos como el toque de queda. En ese contexto, el 23 de octubre aparece un mapa de apoyo a la población civil generado y publicitado por el medio local de comunicación alternativo «La Voz de Maipú», como forma de "servicio social» ante los problemas para abastecerse. Por ello, en él se reportan, de nuevo a través de Google My Maps, todos los almacenes y negocios en Maipú, comuna integrante de la capital. En un espectro parecido se podría incluir también el mapa de semáforos fuera de servicio (Figura 5) que el 4 de noviembre ofreció Emol en la misma plataforma de Google, aunque bajo un argumento más próximo al relato gubernamental que abogaba por «una vuelta a la normalidad».

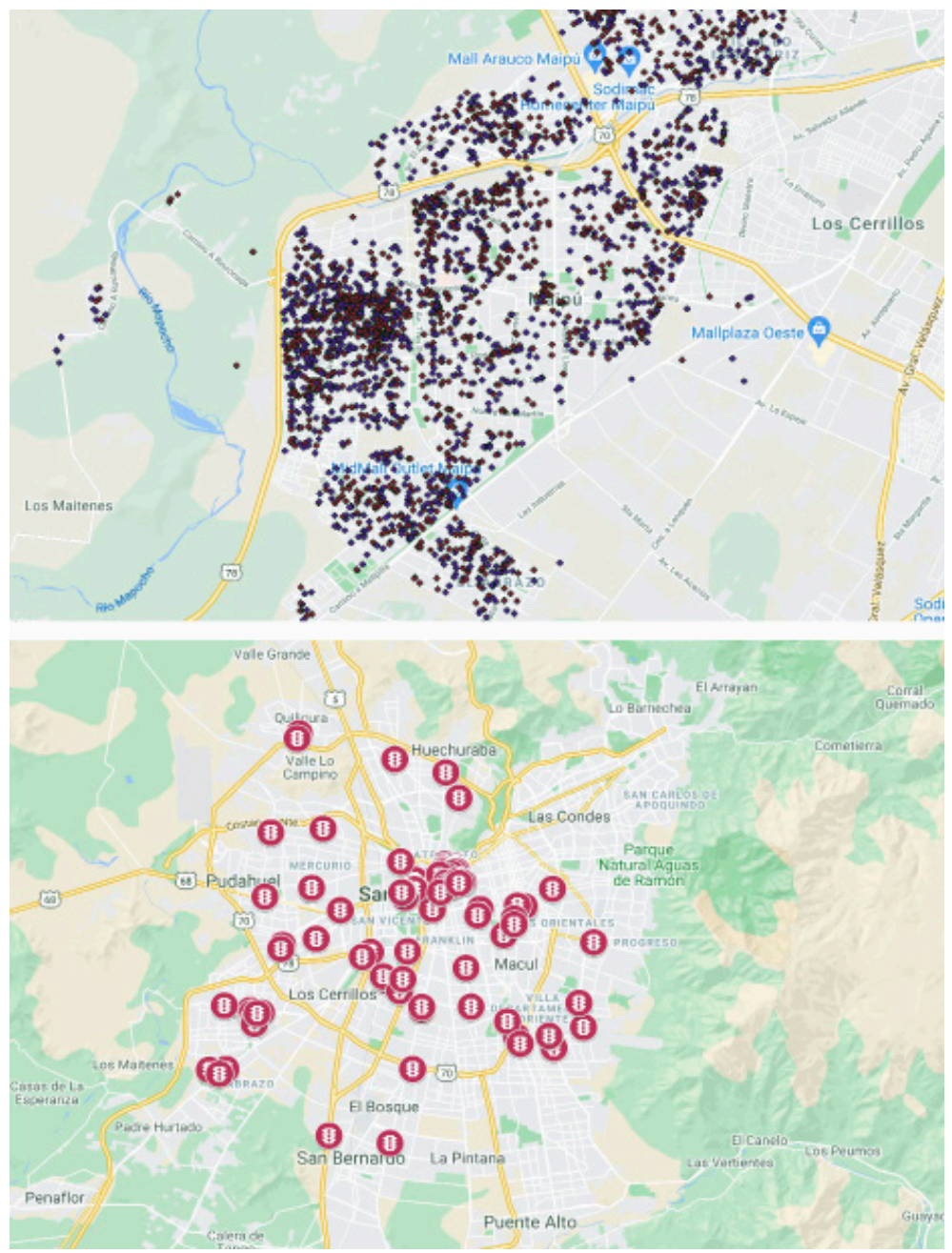

Figura 5. Cartografía sobre almacenes y negocios en Maipú (arriba) y sobre semáforos fuera de servicio en Santiago de Chile (abajo). La Voz de Maipú y Emol. 2019 
Durante el toque de queda, rápidamente se pasó del sentimiento de desamparo al de inseguridad. La represión policial llevó aparejadas violaciones a los derechos humanos que el colectivo «Desclasificación Popular» ha llamado a georreferenciar (fundamentalmente a través de las RRSS) bajo el proyecto «Cartografías de la represión", con el fin de "constatar la producción de espacios represivos como parte de una política de Estado». Iniciativas parejas surgieron en la academia, desde una actividad similar del colectivo estudiantil «Piquete geográfico» de la Pontificia Universidad Católica de Valparaíso hasta la celebración de talleres de cartografía organizados por diversas organizaciones de geógrafos e institutos de la Pontificia Universidad Católica de Chile.

A esta última institución también pertenecen otras actividades, esta vez atribuibles al Centro de Desarrollo Urbano Sustentable (CEDEUS), que puso a disposición del público su herramienta cartográfica colaborativa "Mi ciudad». En ella, se pueden construir de forma anónima y libre mapas de puntos de temática abierta, complementados con descripciones y fotografías. Gracias a esta herramienta han aparecido mapas relacionados con el estallido social que georreferencian desde marchas pacíficas hasta saqueos y disparos de la policía.

En una lucha por el relato, la Corporación de Fomento de la Producción (CORFO), agencia gubernamental, ha elaborado una cartografía siguiendo la misma metodología y plataforma dominante entre la resistencia civil (Google My Maps). En ella se realiza un catastro de las pequeñas y medianas empresas (Pymes) «afectadas por la contingencia nacional», incluidas presumiblemente por sus propietarios en la base de datos. Este mapa, publicitado a través del hashtag \#elijopyme, presenta una serie de registros en bloque no contrastables debido a que, a diferencia de los ejemplos vistos anteriormente, la información no es descargable.

Esta disputa adquiere su culmen a la hora de dominar un espacio, y parte de esta dominación recae en la capacidad de darle nombre. Durante este proceso se han vivido cambios espontáneos en la toponimia de la ciudad en un intento de construir una nueva imagen referente, forma a través de la cual ejercer apropiación y acción sobre el espacio geográfico (NúÑEZ, ZAMBRA y ALISTE, 2017). El más notable de entre ellos es el que afecta al epicentro físico de las protestas, oficialmente denominado como Plaza Baquedano (en honor al general y presidente efímero de Chile durante 1891), y que en su origen, según DE RAMón y Gross (1985), fue nombrado Plaza La Serena (1875-1892), para pasar a designarse Plaza Colón (en la conmemoración del cuarto centenario de la llegada de los europeos a América) y más recientemente (1910-1928), Plaza Italia. La cuarta nominación tras la original y consecuente resignificación se produjo el 11 de noviembre de 2019, cuando las etiquetas de Google Maps fueron modificadas en un ejercicio de "ciberactivismo" o "activismo virtual», para renombrar este lugar como «Plaza de la Dignidad». Esto, que aún no ha alcanzado oficialidad, adquirió materialidad dos días después mediante un grafiti de gran formato en el asfalto de la misma plaza.

Este hecho responde a un imaginario social (nuevo y ampliamente compartido) de este espacio, que lo interpreta como puesto de resistencia cívica ante la dura represión estatal. No en vano, en este sector han tenido lugar continuas movilizaciones, siendo la del 25 de octubre de 2019, la más multitudinaria. Ese día, tras el llamado a realizar "La marcha más grande de Chile», se reunieron 1,2 millones de personas según las cifras de la Intendencia Metropolitana.

De hecho, este registro ha sido fruto de controversia, por lo cual han 
aparecido varias respuestas desde la academia (particularmente por el profesor Pablo Guzmán del Instituto de Estudios Urbanos y Territoriales de la Pontificia Universidad Católica de Chile) y otros expertos profesionales del campo de la ingeniería que, si bien no se han plasmado todavía en estudios científicos publicados, sí fueron dados a conocer en las RRSS.

De esta forma, la producción cartográfica no sólo ha tenido un carácter colaborativo y guiado por asociaciones y colectivos, sino que parte de ella ha sido fruto de un trabajo individual. Estas cartografías han aprovechado toda la potencialidad de las RRSS y la coincidencia con hashtags no relacionados con la protesta, como \#30DayMapChallenge, para difundir su mensaje, en muchas ocasiones contrario al oficialismo. En ellas predomina una participación académica y con formación especializada, que combinada con la producción de cartografía colaborativa aísla el discurso del oficialismo.

\section{DISCUSIÓN}

El desarrollo tecnológico y su democratización ha sido un componente diferenciador con respecto al papel de la cartografía y su incidencia en este tipo de procesos. Los nuevos mapas han sido eficaces por 4 ventajas comparativas, todas ellas consecuencias del progreso técnico e interrelacionadas.

En primer lugar, la gratuidad y su amplia difusión. El acceso libre a un entorno digital a través de una extensa gama de dispositivos móviles ha permitido transversalidad social y la multiplicación de los actores implicados en la producción cartográfica y en la recepción del resultado. Esta influencia ha resultado mayor si se considera que los agentes participantes son en su mayoría nativos digitales, o bien cuentan con un alto grado de inmersión.

En segundo lugar, la anulación de las limitaciones espaciales (y temporales). Durante un contexto crítico y de inseguridad, así como de suspensión de derechos de movimiento y reunión, la generación de la información al igual que su transmisión y recepción ha estado garantizada por las redes móviles. Este esquema ha permitido, además, un reemplazo en la fuente de datos, es decir, de los informantes que mayoritariamente se encontraban en las calles. Gracias a esto ha aumentado la resiliencia de un movimiento que ha avanzado mediante una dinámica de enjambre (SÁNCHEZ, 2012), que sorteaba e inutilizaba los esfuerzos del gobierno por reestablecer el orden público en determinados enclaves urbanos para sofocar las protestas.

Seguidamente, la inmediatez, consecuencia de los dos elementos anteriores. La producción cartográfica se ha realizado mayoritariamente con aportes voluntarios y masivos, que han reducido a la mínima expresión el proceso de captación de datos y su publicación. El mapeo digital y en tiempo real, como en otros movimientos sociales recientes ocurridos globalmente (15-M en Madrid, Ocuppy Wall Street en Nueva York o el 15-O de 2011 a nivel mundial), ha permitido la consolidación y reproducción "viral" del estallido, aportándole inmediata visibilidad nacional e internacional (NOFRE, 2013). Por esta razón y la naturaleza de sus contenidos, estos mapas son eminentemente una cartografía de uso (durante los eventos) y no de análisis. Su objetivo se asemeja parcialmente a las cartografías del peligro (HENDEL, 2020) y los mapas feministas topofóbicos (TORO y OCHOA, 2017) por cuanto expone espacios peligrosos, pero difieren de 
estos por su escasa latencia. Por lo tanto, esta es una cartografía de alarma (DE Sото, 2014), que además de servir como vector de reproducción del movimiento por su capacidad para localizar eventos y aglutinar personas, se utiliza en Santiago durante momentos críticos como un mapa de resguardo y cuidado (generando movimientos de repliegue). Su trasversalidad social y rapidez, da buena cuenta del carácter espontáneo de lo producido, lo que contrarresta el mensaje oficialista que defiende la confluencia de estrategias premeditadas en su contra.

Por último, resulta principal su intercomunicación. Esto redunda en un mayor orden y capacidad evolutiva. El avance en paralelo de distintas iniciativas con diferentes orígenes, pero cuyos resultados eran de acceso público e inmediato, ha impedido la existencia de duplicidades. Cuando estas eran detectadas, los contenidos de los mapas variaban. Otro factor que ha introducido cambios ha sido el mensaje gubernamental y mediático, contrarrestado desde la cartografía. Esto ha provocado que cada cartografía se convierta rápidamente en referencia dentro de la temática que aborda y en contraparte del oficialismo.

\section{CONCLUSIONES}

La cartografía generada en Chile debido al estallido social vivido el 18 de octubre de 2019 ha sido parte esencial del mismo y elemento fundamental para su pervivencia en el tiempo. Esta resistencia ha resultado a su vez indispensable para cosechar logros tan importantes como el plebiscito constitucional pactado para el 26 de abril de 2020, aunque pospuesto hasta el 25 de octubre del mismo año a tenor de la crisis sanitaria desatada por el Covid-19, y del que se ha originado un nuevo proceso constituyente a tenor de un $78,28 \%$ de sufragios favorables a la redacción de una nueva Constitución para Chile.

Los mapas generados han sido consumidos por la sociedad desde sus hogares y las calles con distintos propósitos, que eran cambiantes según las necesidades y la evolución del conflicto. La adaptación del resultado cartográfico es fruto de esta retroalimentación.

Tal y como indican Moral y Merino (2018:271) este tipo de mapas «nacen en un contexto efímero con una voluntad de documento registral, organizativo y de difusión de ideas - tácticas que definan una nueva ciudad", y en este caso específico, pretenden alcanzar un nuevo modelo-país.

Prueba del éxito e influencia de la cartografía colaborativa es que desde el gobierno se ha intentado replicar su metodología e, incluso, se han utilizado sus mismos canales de captación y difusión. Esto demuestra lo afirmado por LACOSTE (1977) sobre la importancia del espacio, la geografía y su representación gráfica, esto es, los mapas, en la confrontación entre partes, anunciada para Chile por el Presidente de la República. ${ }^{10}$ Así, en la cancha de juego chilena de un lado se encuentra el gobierno y su ponderación del orden público, y de frente, la cartografía socialmente construida, con apoyos puntuales e individuales desde la academia y otros sectores, en defensa de los derechos humanos.

Este tipo de eventos y análisis demuestran que el estudio de la meta-cartografía en un entorno y coyuntura digital como la actual debe ser tenido muy en cuenta

10 Tras tres días desde el estallido social, el 21 de octubre, y momentos antes de declarar el estado de emergencia y toque de queda, el presidente Sebastián Piñera declaró: «estamos en guerra contra un enemigo poderoso». 
por la geografía humana. Tan importante es el resultado final como la forma de construirlo, el modo de publicarla, el tipo de acceso y las características, origen y número de sus productores y usuarios. La cartografía, que fue patrimonializada por el poder institucional cada vez se muestra más "democratizada», lo cual implica oportunidades pero también nuevos riesgos que deben ser examinados.

\section{REFERENCIAS}

ACNUDH. (2019): Informe sobre la misión a Chile "30 de octubre-22 de noviembre de 2019". Disponible online.

ANIÑIR, D.; CANDINA, A. (2020): «Estallido social: elementos para una genealogía de las violencias», Meridional. Revista Chilena de Estudios Latinoamericanos, 14: 241-246. doi: 10.5354/0719-4862.2020.57136

Atria, F. (2013): Neoliberalismo con rostro humano: veinte años después, Catalonia, Santiago de Chile.

BorgiAS, S.L. (2018): “"Subsidizing the State:" The political ecology and legal geography of social movements in Chilean water governance», Geoforum, 95: 87-101. doi: https://doi.org/10.1016/j.geoforum.2018.06.017

BRAVO, V. (2012): «Neoliberalismo, protesta popular y transición en Chile 19731989», Politica y Cultura, 37: 85-112.

Bruey, A.J. (2012): "Limitless Land and the Redefinition of Rights: Popular Mobilisation and the Limits of Neoliberalism in Chile, 1973-1985», Journal of Latin American Studies, 44 (3): 523-552. doi: https://doi.org/10.1017/ S0022216X12000399

CEPAL (2019): Panorama social de América Latina, CEPAL-ONU, Santiago de Chile.

CinI, L.; GuZMÁn-ConCHA, C. (2017): «Student movements in the age of austerity. The cases of Chile and England», Social Movement Studies, 16 (5): 623-628. doi: https://doi.org/10.1080/14742837.2017.1331122

Denegri, M.; Palavecinos, M.; Gempr, R.; CAPRILe, C. (2005): «Socialização econômica em famílias chilenas de classe média: educando cidadãos ou consumidores?», Psicologia E Sociedade, 17 (2): 88-98.

DisI, R. (2018): «Sentenced to Debt: Explaining Student Mobilization in Chile», Latin American Research Review, 53 (3):448-465. doi: https:/ / doi.org/10.25222/ larr.395

De Julios, A. (1995): «Individualismo y modernidad. Una lectura alternativa», Anuario de Filosofía del Derecho, 12: 239-268.

De Soto, P. (2014): «Los mapas del \#15M: el arte de la cartografía de la multitud conectada», en E. Serrano, A. Calleja, A. Monterde y J. Toret (eds.), 15MP2P. Una mirada transdisciplinar del 15M, Universtitat Oberta de Catalunya, Barcelona: 362-387.

Di Giminiani, P.; GonzÁlez, M. (2018): «Who Owns the Water? The Relation as Unfinished Objectivation in the Mapuche Lived World", Anthropological Forum, 28 (3): 199-216. doi: https:/ / doi.org/10.1080/00664677.2018.1495060

Fernández, I.C.; Manuel-Navarrete, D.; Torres-Salinas, R. (2016): «Breaking Resilient Patterns of Inequality in Santiago de Chile: Challenges to Navigate towards a More Sustainable City", Sustainability, 8: 820. doi: https://doi. org/10.3390/su8080820 
GARRETON, M. (2017): "City profile: Actually existing neoliberalism in Greater Santiago", Cities, 65:32-50. doi: http:/ / dx.doi.org/10.1016/j.cities.2017.02.005

Gerding, C.; Fuentes, M.; Kotz, G. (2012): "Anglicismos y aculturación en la sociedad chilena», Onomázein, 25: 139-162.

GutiéRreZ, Ó. (2020): «Razones del levantamiento social en Chile. Necropolítica como paradigma de Estado», Universum, 35 (1): 104-126.

HaRveY, D. (2007): Breve historia del Neoliberalismo, Akal, Madrid.

HarveY, D. (2012): El enigma del capital y las crisis del capitalismo, Akal, Madrid.

Harvey, D. (2019): Marx, El capital y la locura de la razón económica, Akal, Madrid.

Hendel, V. (2020): "Cartografías del peligro. Desplazamientos, migración, fronteras y violencias desde la experiencia de los jóvenes en un barrio del Gran Buenos Aires, Argentina (2018-2019)», Historia y Sociedad, 39: 184-212. doi: http:/ / dx.doi.org/10.15446/hys.n39.82576

Hidalgo, R. (1999): «La vivienda social en Chile: La acción del Estado en un siglo de planes y programas», Scripta Nova, 3 (45). Disponible online.

Hidalgo, R.; Alvarado, V.; Santana, D. (2017): «La espacialidad neoliberal de la producción de vivienda social en las áreas metropolitanas de Valparaíso y Santiago (1990-2014): ¿hacia la construcción ideológica de un rostro humano?», Cadernos Metrópole, 19 (39): 513-535. doi: http://dx.doi.org/10.1590/22369996.2017-3907

Humeres, M. (2019): “"Gane usted y ayude a la Teletón”: mecanismos neoliberales en la gestión del bienestar», Convergencia. Revista de Ciencias Sociales, 81: 1-24. doi: https:/ / doi.org/10.29101/crcs.v26i81.11641

InZunZA, J., Assael, J., CoRnejo, R., y Redondo, J. (2019): «Public education and student movements: the Chilean rebellion under a neoliberal experiment», British Journal of Sociology of Education, 40 (4): 490-506. doi: https:/ / doi.org/1 0.1080/01425692.2019.1590179

JANOSCHKA, M.; HidALGO, R. (2014): «La ciudad neoliberal: estímulos de reflexión crítica», en R. HidALGo y M. JANOSCHKA (eds.), La ciudad neoliberal. Gentrificación y exclusión en Santiago de Chile, Buenos Aires, Ciudad de México y Madrid, Serie GeoLibros, Santiago de Chile: 7-32.

Jiménez, V.; Hidalgo, R.; Campesino, A.J.; Alvarado, V. (2018): «Normalización del modelo neoliberal de expansión residencial más allá del límite urbano en Chile y España», EURE, 44 (132): 27-46. doi: http:/ /dx.doi.org/10.4067/ s0250-71612018000200027

KeELEY, B. (2018): Desigualdad de ingresos. La brecha entre ricos y pobres, OCDE, París. LACOSTE, Y. (1977): La geografía: un arma para la guerra, Anagrama, Barcelona.

LetelieR, L. F.; TAPIA, V.C.; IRAZÁBAL, C.; BoyCo, P. (2019): «Políticas de fragmentación vs. prácticas de articulación: limitaciones y retos del barrio como dispositivo de planificación neoliberal en Chile», Boletín de la Asociación de Geógrafos Españoles, 81: 1-38. doi: http:/ / dx.doi.org/10.21138/bage.2698

MÉndeZ, M.L.; OTERO, G. (2018): «Neighbourhood conflicts, socio-spatial inequalities, and residential stigmatisation in Santiago, Chile», Cities 74: 7582. doi: https:/ / doi.org/10.1016/j.cities.2017.11.005

Maturana, F.; Fuenzalida, M.; ArenAs, F.; HenríQuez, C. (2017): «La planificación territorial en Chile y el proceso de descentralización», en C. VIAL y J. Hernández (eds.), ¿Para qué descentralizar? Centralismo y políticas públicas en Chile: Análisis y Evaluación por Sectores, Instituto Chileno de Estudios 
Municipales y Universidad Autónoma de Chile, Santiago de Chile: 181-208.

Moral, F.; Merino, E. (2018): «Cartografías urbanas: la representación gráfica del conflicto en los espacios públicos», Polipapers, 23 (32): 262-273. doi: https:/ / doi.org/10.4995/ega.2018.7973

MuÑoz, C. (2007): «Vivienda progresiva, un programa del sector público que se potenció en el hábitat rural chileno", Revista INVI, 22 (59): 132-150.

Navarrete-Hernández, P.; Toro, F. (2019): «Urban Systems of Accumulation: Half a Century of Chilean Neoliberal Urban Policies», Antipode, 51 (3): 899-926. doi: https://doi.org/10.1111/anti.12504

Nicolosi, E.; French, J.; Medina, R. (2019): «Add to the map! Evaluating digitally mediated participatory mapping for grassroots sustainabilities», The Geographical Journal, 185: 1-14. doi: https:/ / doi.org/10.1111/geoj.12315

Nofre, J. (2013): “Cartografías de la indignación», Ar@cne, 169: 1-20.

NúÑEZ, A.; ZAMBRA, A.; Aliste, E. (2017): «El poder de los mapas, los mapas del poder: la construcción del saber geográfico de Patagonia-Aysén», Universum, 32 (2): 149-162.

Pizarro, R. (2020): «Chile: rebelión contra el Estado subsidiario», El trimestre económico, 87 (346): 333-365. doi: 10.20430/ete.v87i346.1055

ROMÁN, Á.; BARTON, J.R. (2018): «Los supuestos del pensamiento urbano en Chile: justicia y equidad en la planificación de las ciudades», en F. ENCINAS, A. Wechsler, W. Bustamante, y F. Díaz (eds.), Intersecciones: II Congreso Interdisciplinario de Investigación en Arquitectura, Diseño, Ciudad y Territorio, Ediciones ARQ, Santiago de Chile: 14-27.

SAKELLARIOU, D.; ROTAROU, E.S. (2017): «The effects of neoliberal policies on access to healthcare for people with disabilities», International Journal for Equity in Health, 16(199): 1-8. doi: https:/ / doi.org/10.1186/s12939-017-0699-3

SÁNCHEZ, R. (2012): «El 15M como insurrección del cuerpo-máquina», Anthropos: Huellas del conocimiento, 234: 216-224.

Stiglitz, J. (2012): El precio de la desigualdad, Taurus, Madrid.

TAPIA, V. (2018): "Geografías de la contención: el rol de las políticas de escala barrial en el Chile neoliberal», Scripta Nova, 22 (592).

De Castro, S.; Méndez, J.C. (1992): El ladrillo. Bases de la Política Económica del Gobierno Militar Chileno, Centro de Estudios Públicos, Santiago de Chile.

De Ramón, A.; Gross, P. (1985): Santiago de Chile: Características histórico-ambientales, 1891-1924, Monografías de Nueva Historia, Londres.

PICSA. (2019): Creating an Inclusive Prosperity Cities Index. Background and Methodology, Disponible online.

Ritzer, G. y JuRgenson, N. (2010): «Production, Consumption, Prosumption: The nature of capitalism in the age of the digital 'prosumer'», Journal of Consumer Culture, 10(1): 13-36. doi: https:/ / doi.org/10.1177/1469540509354673

Sullivan-WileY, K.A.; SHort, A.G.; CASELlas, J.P. (2019): «Mapping vulnerability: Opportunities and limitations of participatory community mapping», Applied Geography, 105: 47-57. doi: https:// doi.org/10.1016/j.apgeog.2019.02.008

ToRO, J.; OcHOA, M. (2017): «Violencia de género y ciudad: cartografías feministas del temor y el miedo», Sociedad y economía, 32: 65-84.

Vives, A.; MolinA, A.; GrAY, N.; GonZÁLEZ, F. (2016): «Envejecimiento y trabajo en Chile: propuesta para el monitoreo de la salud laboral», en I. IRARRÁZAVAL, E. Piña, y M. Letelier (eds.), Propuestas para Chile, Centro UC Políticas Públicas, Santiago de Chile: 17-50. 